\title{
Predictive factors of methotrexate treatment success in ectopic pregnancy: A single-center tertiary study
}

\author{
Cigdem Pulatoglu, ${ }^{1}$ Ozan Dogan, ${ }^{2}$ Alper Basbug, ${ }^{3}$ Aski Ellibes Kaya, ${ }^{3}$ Ahmet Yildiz, ${ }^{4}$ Osman Temizkan ${ }^{2}$ \\ ${ }^{1}$ Department of Obstetrics and Gynecology, Bayburt Government Hospital, Bayburt, Turkey \\ ${ }^{2}$ Department of Obstetrics and Gynecology, Sisli Hamidiye Etfal Training and Research Hospital, Istanbul \\ 32Department of Obstetrics and Gynecology, Duzce University Hospital, Duzce, Turkey \\ ${ }^{4}$ Department of Gynecology and Obstetrics, Sakarya University Faculty of Medicine, Sakarya, Turkey
}

\begin{abstract}
OBJECTIVE: It is controversial whether medical or surgical treatment options have more successful results in ectopic pregnancy treatment. Although high pretreatment serum hCG levels have been known to be the most important predictor, the appropriate treatment modality for a specific range of hCG level remains unclear. Furthermore, the variables that make a patient a bad candidate for single-dose methotrexate treatment is unclear.

The aim of this study was to identify predictive factors associated with the success of single-dose methotrexate treatment in women with ectopic pregnancy.

METHODS: In this retrospective study, 101 women with tubal ectopic pregnancies who had been treated with single-dose methotrexate were selected. The gestational ages, pretreatment hCG values, ectopic mass size, and fluid presence in the abdomen were compared between the groups.

RESULTS: The mean age of the patients was $30.6 \pm 5.8$ (range, 19-42) years, and the gestational age at first injection was $7.0 \pm 2.13$ (range, 2.3-13.6) weeks. The overall treatment success rate was $77.2 \%(n=79)$. The mean duration of hospital stay was $4.21 \pm 1.89$ days in the successfully treated group and $6.92 \pm 2.13$ days in the failure group $(p<0.05)$. The rate of treatment failure in patients with abdominal fluid was $37.8 \%$, and it was $12.7 \%$ in the non-fluid group ( $p=0.03$ ). hCG values on days 1,4 , and 7 were significantly higher in the unsuccessful group (3887-2589 mIU/mL, 2814-1287 mIU/mL, and 1119-285 mIU/mL, respectively; $\mathrm{p}<0.05$ ). The cutoff hCG value, which determined the failure of methotrexate treatment, was found to be $1362 \mathrm{mIU} / \mathrm{mL}$.
\end{abstract}

CONCLUSION: In present study, patients with hCG value $<1362 \mathrm{mIU} / \mathrm{mL}$ were found to be good candidates for methotrexate treatment. Although not strictly decisional, this hCG threshold level can be used to decide on the likelihood of methotrexate success or failure. Detection of abdominal fluid on ultrasonography also can be assessed as a bad prognostic factor, but size of ectopic mass does not correlate with methotrexate treatment success.

Keywords: Ectopic pregnancy; methotrexate; single-dose treatment.

Cite this article as: Pulatoglu C, Dogan O, Basbug A, Ellibes Kaya A, Yildiz A, Temizkan O. Predictive factors of methotrexate treatment success in ectopic pregnancy: A single-center tertiary study. North Clin Istanb 2018;5(3):227-231.

Cctopic pregnancy occurs when the developing blastocyst gets implanted at a site other than the endometrium of the uterine cavity. The most common extrauterine location is the fallopian tube, which accounts for $98 \%$ of all ectopic gestations [1]. Ectopic pregnancy is a potentially life-threat- ening condition and accounts for $4 \%-6 \%$ of all maternal death [2]. Although surgical approaches are the mainstay of treatment, advances in early diagnosis facilitated the introduction of medical treatment with methotrexate (MTX) for unruptured ectopic pregnancy [3].

Received: October 03, 2017 Accepted: October 11, 2017 Online: May 23, 2018

Correspondence: Dr. Ozan DOGAN. Sisli Hamidiye Etfal Egitim ve Arastirma Hastanesi, Kadin Hastalikları ve Dogum Klinigi, Istanbul, Turkey. Phone: +90 5055060720 e-mail: ozandogan02@hotmail.com

(c) Copyright 2018 by Istanbul Provincial Directorate of Health - Available online at www.northclinist.com 
MTX is an antimetabolite chemotherapeutic agent that binds to the enzyme dihydrofolate reductase, which is involved in the synthesis of purine nucleotides. This interferes with deoxyribonucleic acid synthesis and disrupts cell multiplication. Its effectiveness on trophoblastic tissue has been well established and is derived from experience gained in using MTX in the treatment of hydatiform moles and choriocarcinomas. MTX is used in the treatment of ectopic pregnancy as single or multiple intramuscular injections [4-6].

The 2 most commonly used protocols for MTX administration are single-dose and multiple-dose regimens (4 MTX doses that alternate with oral leucovorin). A meta-analysis reported that using a single-dose regimen is associated with a higher failure rate than using the multidose regimen (12\% vs. $7 \%$ ) [7]. Previous studies have also reported similar effectiveness between single-dose and multi-dose treatments [8]. Moreover, single-dose regimen is found to be less expensive, requires less intensive monitoring, and does not require folinic acid rescue [7].

Although high pretreatment serum human chorionic gonadotropin $\beta$ subunit (hCG- $\beta$ ) levels have been known to be the most important predictor associated with medical treatment failure, which treatment modality is appropriate for a specific range of pretreatment serum hCG level remains unclear [9].

The aim of this study was to identify predictive factors associated with the success of response to treatment with single-dose MTX regimen in women with tubal ectopic pregnancy.

\section{MATERIALS AND METHODS}

We conducted a retrospective study of 101 consecutive women with tubal ectopic pregnancies who had been treated with single-dose MTX from November 2015 to July 2016 at Sisli Hamidiye Etfal Training and Research Hospital in Istanbul, Turkey. The study was approved by the local ethics committee, and the study protocol adhered to the tenets of the Declaration of Helsinki.

Patients who were $>18$ years old, hemodynamically stable with unruptured tubal ectopic pregnancy, did not have hepatic, hematologic, or renal disease, and treated with intramuscular MTX were included. Patients who were $<18$ years old, hemodynamically unstable, had other localizations of ectopic pregnancy (abdominal, ovarian, cervical, cesarean scar), had unknown treatment results, or underwent surgery directly before medical treatment were excluded. Patients who had ectopic focus with positive fetal cardiac activity direct underwent surgery and were not included in the study.

Demographic data such as age, parity, gestation week by last menstrual period, previous infertility treatment, previous history of ectopic pregnancy, use of intrauterine contraceptive device, and clinical presentation such as abdominal pain, vaginal bleeding, and amenorrhea were documented from patients' medical files.

Initial free hCG- $\beta$ levels of all patients who had been treated with a single $50 \mathrm{mg} / \mathrm{m}^{2}$ (body surface area) dose of intramuscular MTX according to the tubal ectopic pregnancy treatment protocol $[10,11]$ were recorded. The size of ectopic mass, presence of ectopic cardiac activity, and presence of abdominal fluid around the liver and between the loops of intestine that have been detected by both abdominal and vaginal ultrasonographic examination were documented. Following MTX administration, serum hCG levels on days 4 and 7 were recorded. If the decrease in hCG level between days 4 and 7 after MTX administration was $>15 \%$, it was accepted as successful medical treatment. hCG levels were monitored weekly until it was undetectable. If hCG level between days 4 and 7 failed to fall $>15 \%$ of the previous serum hCG level, treatment with single-dose MTX was considered unsuccessful and a second dose was administered. No complications or side effects were observed among patients treated with MTX. When the patient exhibited signs or symptoms of ruptured ectopic pregnancy, had persistence of ectopic cardiac activity, or showed insufficient fall or rise of serum hCG levels, medical treatment was considered unsuccessful and surgery was indicated.

The statistical analyses were obtained using Statistical Package for the Social Sciences software, version 17.0. Results were considered as statistically significant when the P-value was $<0.05$.

\section{RESULTS}

A total of 101 patients who received MTX treatment for ectopic pregnancy in the 9-month period were included in the study. The mean age of the patients was $30.6 \pm 5.8$ years. The mean gestational age at first MTX injection was $7.0 \pm 2.13$ weeks. Of the 101 patients, 34 were multiparous, 26 were primiparous, and 41 were nulliparous. Six of the nulliparous patients were found to be primer infertile. The symptoms of patients at the time of admission to hospital were metrorrhagia for 46 (45.5\%) patients and pain for $29(28.7 \%)$ patients. Twenty-six (25.7\%) patients presented to the hospital just for abnormal hCG levels although they were asymptomatic. Ectopic focus was observed in $75 \%$ of patients. Overall, 
TABLE 1. Characteristics of patients and ectopic pregnancy

\begin{tabular}{lccc} 
Characteristics & $\begin{array}{c}\text { Failure of MTX } \\
\text { treatment; } \mathrm{n}=22\end{array}$ & $\begin{array}{c}\text { Successful MTX } \\
\text { treatment; } \mathrm{n}=79\end{array}$ & $\mathrm{p}$ \\
\hline Age (years) & 30.68 & 30.45 & 0.41 \\
Gravidity & 2.65 & 2.32 & 0.387 \\
Parity & 0.97 & 0.86 & 0.61 \\
D1 hCG level $(\mathrm{mIU} / \mathrm{mL})$ & 3887 & 2589 & 0.017 \\
D4 hCG level $(\mathrm{mIU} / \mathrm{mL})$ & 2814 & 1287 & 0.002 \\
D7 hCG level $(\mathrm{mIU} / \mathrm{mL})$ & 1119 & 285 & 0.001 \\
Size of ectopic focus $(\mathrm{mm})$ & 28.45 & 24.70 & 0.521 \\
Gestational ages $($ weeks) & 7.02 & 6.91 & 0.47 \\
Duration of hospital stay (days) & 6.92 & 4.21 & $<0.05$ \\
Presence of fluid in the abdomen (\%) & 37.8 & 12.7 & 0.03 \\
\hline
\end{tabular}

Significant scores with $p<0.05$ are bolded; D0: the day of first MTX injection.

$28 \%$ of the patients had an ectopic focal size $>3.5 \mathrm{~cm}$ in diameter, and $37 \%$ had fluid in their abdomen.

The mean pretreatment hCG level for all patients was $2874( \pm 2277) \mathrm{mIU} / \mathrm{mL}$. The MTX doses used ranged from 50 to $100 \mathrm{mg}$, with a mean of $71.37 \pm 18.40 \mathrm{mg}$. Overall, $14 \%$ of the patients needed a second MTX dose. Second doses were administered after a mean of $7.8( \pm 6.9)$ days, when needed. Overall, $28.4 \%$ of patients who had received a second MTX dose required surgical treatment. A total of 22 patients underwent surgical treatment after an average of $4.8 \pm 3.1$ (range, 2-9) days due to findings of ectopic pregnancy rupture or unresponsiveness to medical treatment. The overall success rate of medical treatment with MTX was $77.2 \%(n=79)$. In patients in whom medical treatment failed, the hCG level at first day of injection was $3887 \pm 3300 \mathrm{mIU} / \mathrm{mL}$, whereas in the successfully treated group, this value was found to be $2589 \pm 1784 \mathrm{mIU} / \mathrm{mL}$. The hCG levels were significantly different between the 2 groups $(\mathrm{p}<0.017)$. The mean duration of hospital stay was $4.21 \pm 1.89$ days in the successfully treated group and $6.92 \pm 2.13$ days in the group with unsuccessful medical treatment $(p<0.05)$. In both groups, there was no statistically significant difference in terms of the mean age of patients (30.4 and 30.68 years), the gestational age at time of diagnosis, size of ectopic focus, number of pregnancies, infertility, abortion, and ectopic pregnancy history $(p>0.05)$.

There was significant difference between the 2 groups in terms of fluid presence in the abdomen, as detected by ultrasonography with abdominal probe. The rate of failure of medical treatment in patients with fluid in the ultrasonography was $37.8 \%$ and $12.7 \%$ in the non-fluid group ( $\mathrm{p}=0.03)$. hCG values on days 1,4 , and 7 were sig- nificantly higher in the unsuccessful group (3887-2589 $\mathrm{mIU} / \mathrm{mL}, 2814-1287 \mathrm{mIU} / \mathrm{mL}$, and $1119-285 \mathrm{mIU} /$ $\mathrm{mL})(\mathrm{p}<0.05)$ (Table 1$)$.

The cutoff hCG value, which determined the failure of MTX treatment with $71.8 \%$ sensitivity and $68.2 \%$ specificity in the ROC curve analysis, was found to be 1362 $\mathrm{mIU} / \mathrm{mL}$. In patients with hCG levels $>1362 \mathrm{mIU} / \mathrm{mL}$, the failure rate was $23.9 \%$, while at lower values, the failure rate was $17.9 \%$, which was not significant (Fig. 1 ).

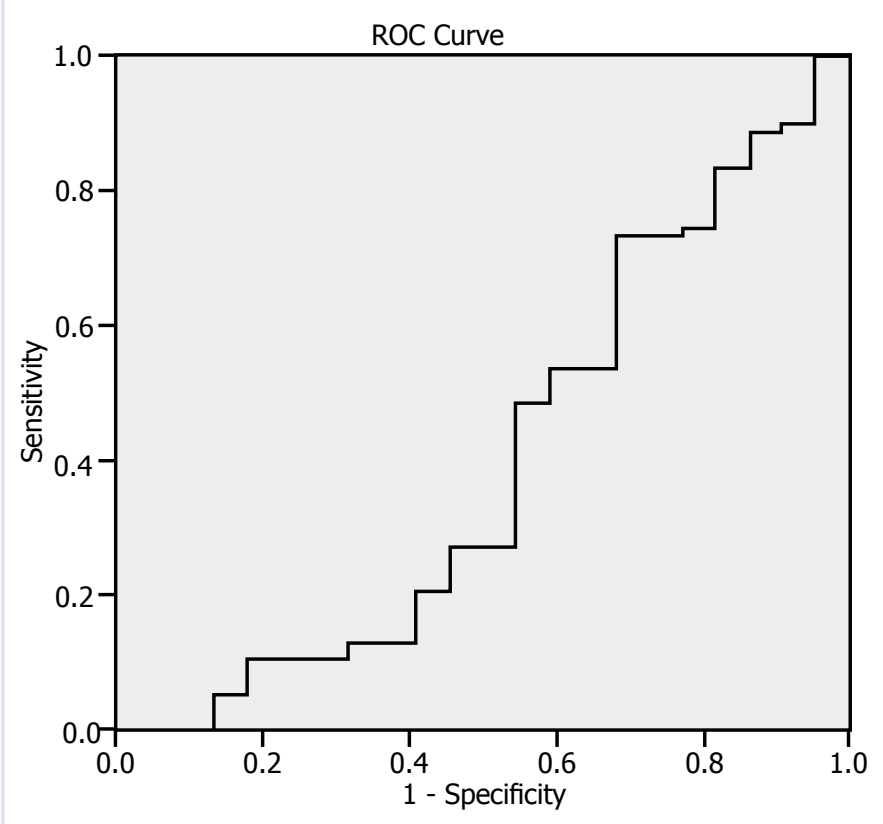

FIGURE 1. ROC curve for the prognostic value of baseline hCG level (IU/L).

Test Result Variables: hCG at the day of first injection: 0.397. 


\section{DISCUSSION}

Medical treatment of ectopic pregnancy with MTX has become the treatment of choice for hemodynamically stable patients [12]. In our study, the success rate of MTX treatment was found to be $78 \%$ in 101 patients. There are many studies in the literature evaluating the success rates of medical treatment of ectopic pregnancy; it ranges between $75 \%$ and $95 \%$ [13-15]. Rabischong et al. [14], reported a success rate of $75.4 \%$ in a series of 419 patients.

In our study, the mean age of patients was $30.6 \pm 5.8$ years, and there was no correlation between MTX treatment success and maternal age. The mean age of patients in a study conducted by Mirbolouk et al. [16] was $29.34 \pm 5.57$ years, and it was similar in both medical treatment success and failure groups. Another study revealed that increased maternal age reduces MTX treatment success [17].

We found no difference in both groups in terms of gestational age (7.0 \pm 2.13$)$. In the study designed by Mirbolouk et al. [16], the mean gestational age of patients at the time of diagnosis was 6.99 weeks in the successful group and 7.05 weeks in the treatment failure group. In the same study, it has been shown that there was no difference between groups in terms of gravidity and ectopic pregnancy history, similar to those in the present study. However, unlike our study, they found that the number of abortions was significantly higher in the unsuccessful group ( 0.41 and $0.22 ; p=0.03$ ).

The hCG levels on days 1,4 , and 7 in the present study were significantly higher in the treatment failure group (3887-2589 mIU/mL, 2814-1287 mIU/mL, and $1119-285 \mathrm{mIU} / \mathrm{mL}$, respectively; $\mathrm{p}=0.002)$. Similarly, hCG levels on days 1,4 , and 7 were significantly higher in the treatment failure group in Mirbolouk's study (2541$1167 \mathrm{mIU} / \mathrm{mL}, 2807-1132 \mathrm{mIU} / \mathrm{mL}$, and $2723-931$ $\mathrm{mIU} / \mathrm{mL}$, respectively, $\mathrm{p}=0.000)$. There are other studies showing that hCG levels on days 1, 4, and 7 are higher in the MTX treatment failure group $[16,18]$.

One of the known factors associated with MTX treatment success is the pretreatment hCG levels, but thresholds reported in the literature vary from $1000 \mathrm{IU} / 1$ to as much as $5000 \mathrm{IU} / \mathrm{l}$. We found that the cutoff $\mathrm{hCG}$ value to predict MTX treatment failure was $1362 \mathrm{mIU} /$ $\mathrm{mL}$ with $68.8 \%$ sensitivity and $71.8 \%$ specificity. In patients with hCG level $>1362 \mathrm{mIU} / \mathrm{mL}$, the failure rate was $23.9 \%$, whereas in patients with lower hCG levels, the failure rate was $17.9 \%$; however, it was not statisti- cally significant. In a study, the failure rate of MTX treatment was 13\% at hCG levels between 5000 and 9999 $\mathrm{mIU} / \mathrm{mL}, 18 \%$ at hCG levels between 10000 and 14999 $\mathrm{mIU} / \mathrm{mL}$, and $32 \%$ at hCG levels $>15000 \mathrm{mIU} / \mathrm{mL}$ [5]. Our threshold value of was similar to Rabischong et al. [14] retained $1300 \mathrm{IU} / \mathrm{L}$ for their 2011 study. The study conducted by Markwitz et al. [19] revealed the cutoff hCG level for determining MTX treatment failure as $1790 \mathrm{mIU} / \mathrm{mL}$ with a sensitivity and specificity of $81 \%$ and $78 \%$, respectively. In the study by Vaswani et al. [20], the cutoff hCG level was $5921 \mathrm{mIU} / \mathrm{mL}$ with a sensitivity of $100 \%$ and specificity of $93.3 \%$.

In our study, no significant correlation was found between ectopic focus size and treatment success. This result may be due to the fact that the proportion of patients $(72 \%)$ with ectopic focus $<3.5 \mathrm{~cm}$ was too large in our study. Gnisci et al. [21] demonstrated that as the size of ectopic mass increased, so did the failure rates, but this association was not statistically significant. In some studies, the use of MTX treatment has been shown to have a higher success rate when the treatment was limited to patients with ectopic focus size $<3-4 \mathrm{~cm}$ [4]. The ectopic focus size was found to be $28.30 \mathrm{~mm}$ in the treatment success group and $30.2 \mathrm{~mm}$ in the treatment failure group in Mirbolouk's study [16].

Peritoneal fluid, detected by ultrasonography, may be the finding of tubal rupture or tubal abortion and used frequently as an exclusion criterion for MTX treatment. As a result of culdocentesis performed in ectopic pregnancies, blood was detected in $70 \%-83 \%$ of the patients and tubal rupture was observed in only $50 \%-62 \%$ of them [17-22]. In our study, the rate of failure of medical treatment in patients with abdominal fluid, as detected by ultrasonography, was found to be $37.8 \%(12.7 \%$, $\mathrm{p}<0.03)$. In a large case series, free fluid in the abdomen was not associated with medical treatment failure [4]. The main limitations of our study are its retrospective nature and small number of patient series.

\section{CONCLUSION}

The patients who will respond well to MTX treatment for ectopic pregnancy can be chosen by the initial serum B-hCG levels. Better results can be expected from patients with hCG levels $<1362 \mathrm{mIU} / \mathrm{mL}$. Although not strictly decisional, this hCG threshold level can be used to decide on the likelihood of MTX success or failure. Presence of abdominal fluid on ultrasonography can be assessed as a bad prognostic factor for medical treatment. 
Size of ectopic mass was not statistically correlated with MTX treatment success. The retrospective nature of the study and small sample size were the limitations of this study. Prospective studies with larger populations are required to support our findings.

Conflict of Interest: No conflict of interest was declared by the authors.

Financial Disclosure: The authors declared that this study has received no financial support.

Authorship Contributions: Concept - C.P.; Design - C.P., O.T.; Supervision - A.B.; Materials - C.P.; Data collection \&/or processing - C.P., O.D.; Analysis and/or interpretation - A.E.K., O.T.; Writing C.P., O.D.; Critical review - A.Y.

\section{REFERENCES}

1. Bouyer J, Coste J, Fernandez H, Pouly JL, Job-Spira N. Sites of ectopic pregnancy: a 10 year population-based study of 1800 cases. Hum Reprod 2002;17:3224-30. [CrossRef]

2. Centers for Disease Control and Prevention (CDC). Ectopic pregnancy mortality - Florida, 2009-2010. MMWR Morb Mortal Wkly Rep 2012;61:106-9.

3. Oron G, Tulandi T. A pragmatic and evidence-based management of ectopic pregnancy. J Minim Invasive Gynecol 2013;20:446-54.

4. Hoover KW, Tao G, Kent CK. Trends in the diagnosis and treatment of ectopic pregnancy in the United States. Obstet Gynecol 2010;115:495-502. [CrossRef]

5. Menon S, Colins J, Barnhart KT. Establishing a human chorionic gonadotropin cutoff to guide methotrexate treatment of ectopic pregnancy: a systematic review. Fertil Steril Mar 2007;87:481-4. [CrossRef]

6. Thurman AR, Cornelius M, Korte JE, Fylstra DL. An alternative monitoring protocol for single-dose methotrexate therapy in ectopic pregnancy. Am J Obstet Gynecol 2010;202:139.e1-6. [CrossRef]

7. Barnhart KT, Gosman G, Ashby R, Sammel M. The medical management of ectopic pregnancy: a meta-analysis comparing "single dose" and "multidose" regimens. Obstet Gynecol 2003;101:778-84. [CrossRef]

8. Guvendag Guven ES, Dilbaz S, Dilbaz B, Aykan Yildirim B, Akdag D, Haberal A. Comparison of single and multiple dose methotrexate therapy for unruptured tubal ectopic pregnancy: a prospective randomized study. Acta Obstet Gynecol Scand 2010;89:889-95. [CrossRef]
9. Helmy S, Bader Y, Pablik E, Tiringer D, Pils S, Laml T, et al. Cut-off value of initial serum $\beta$-hCG level predicting a successful MTX therapy in tubal ectopic pregnancy: a retrospective cohort study. Eur J Obstet Gynecol Reprod Biol 2014;179:175-80. [CrossRef]

10. Barnhart KT. Clinical practice. Ectopic pregnancy. N Engl J Med 2009;361:379-87. [CrossRef]

11. American College of Obstetricians and Gynecologists. ACOG Practice Bulletin No. 94: Medical management of ectopic pregnancy. Obstet Gynecol 2008;111:1479-85. [CrossRef]

12. Lipscomb GH, Stovall TG, Ling FW. Nonsurgical treatment of ectopic pregnancy. N Engl J Med 2000;343:1325-9. [CrossRef]

13. Lipscomb GH, Givens VM, Meyer NL, Bran D. Comparison of multidose and single-dose methotrexate protocols for the treatment of ectopic pregnancy. Am J Obstet Gynecol 2005;192:1844-8. [CrossRef]

14. Rabischong B, Tran X, Sleiman A.A, Larraín D, Jaffeux P, Aublet-Cuvelier $B$, et al. Predictive factors of failure in management of ectopic pregnancy with single-dose methotrexate: a general population-based analysis from the Auvergne register, France. Fertil Steril 2011;95:401-4. [CrossRef]

15. Orozco EM, Sánchez-Durán MA, Bello-Muñoz JC, Sagalá J, Carreras E, Roura LC. B-hCG and prediction of therapeutic success in ectopic pregnancies treated with methotrexate, results from a prospective observational study. J Matern Fetal Neonatal Med 2015;28:695-9.

16. Mirbolouk F, Yousefnezhad A, Ghanbari A. Predicting factors of medical treatment success with single dose methotrexate in tubal ectopic pregnancy: a retrospective study. Iran J Reprod Med 2015;13:351-4.

17. Panti A, Ikechukwu NE, lukman OO, Yakubu A, Egondu SC, Tanko BA. Ectopic pregnancy at Usmanu Danfodiyo University Teaching Hospital Sokoto: a ten-year review. Annals of Nigerian Medicine 2012;6:87-91.

18. Cohen A, Bibi G, Almog B, Tsafrir Z, Levin I. Second-dose methotrexate in ectopic pregnancies: the role of beta human chorionic gonadotropin. Fertil Steril 2014;102:1646-9. [CrossRef]

19. Nowak-Markwitz E, Michalak M, Olejnik M, Spaczynski M. Cutoff value of human chorionic gonadotropin in relation to the number of methotrexate cycles in the successful treatment of ectopic pregnancy. Fertil Steril 2009;92:1203-7. [CrossRef]

20. Vaswani PR. Predictors of success of medical management of ectopic pregnancy in a tertiary care hospital in United Arab Emirates. J Clin Diagn Res 2014;8:OC04-8. [CrossRef]

21. Gnisci A, Stefani L, Bottin P, Ohannessian A, Gamerre M, Agostini A. Predictive value of hemoperitoneum for outcome of methotrexate treatment in ectopic pregnancy: an observational comparative study. Ultrasound Obstet Gynecol 2014;43:698-701. [CrossRef]

22. Cartwright PS, Vaughn B, Tuttle D. Culdocentesis and ectopic pregnancy. J Reprod Med 1984;29:88-91. 